\title{
Democracia e eficiência: a difícil relação entre política e economia no debate contemporâneo
}

\author{
MARIA RITA LOUREIRO \\ FERNANDO LUIZ ABRUCIO*
}

\begin{abstract}
Democracy and efficiency: hard relations between politics and economy. Many economists see politics as an irrational activity. They also think state action usually generates market inefficiencies and democratic institutions, such as elections, often work as obstacles to sound economic measures. Showing that vision has been embedded into the main currents of economic thought since the last century, we also argue those ideas are exported to great part of contemporary political science, including the area of public policies. Examining the literature, we show that rational choice political scientists, as the economists, claim governability and effective decisions will be guaranteed mainly through concentrated arenas or through insulated arrangements able to protect policy makers from political interference. In other words, governability depends on the reduction of the political arenas. On the contrary, we reject this technocratic solution of splitting politics from economy. With the support of classical pluralist thinkers, we stand another conception, arguing politics is the privileged social space for building interests and values in an institutionalized way. The difficulties to surpass current international crises since 2008 reveal this is a crucial problem: reducing politics would prevent societies from improving institutional solutions which are the only ones able to give space to emerging conflicts and, then, reach eventual consensus around them.
\end{abstract}

Keywords: democracy; economic efficiency; mainstream economics; political science; rational choice theory.

JEL Classification: A1; B0.

\footnotetext{
* Respectivamente, Professora do Departamento de Gestão Pública da Fundação Getulio Vargas de São Paulo. E-mail: marita.loureiro@gmail.com; Professor do Departamento de Gestão Pública da Fundação Getulio Vargas de São Paulo. E-mail: feabrucio@gmail.com. Submetido: 8/maio/2006; Aprovado: 18/outubro/2011.
} 
"Democratic systems set up processes by which political participants interact with each other to formulate policy. Such interactions produce more intelligent outcomes under many circumstances than highly analytical methods can" (Charles Lindblom \& E. Woodhouse, "The potential intelligence of democracy." (In The policy making process, 1993)

\section{INTRODUÇÃO}

O momento atual é marcado por um paradoxo: de um lado, desde 2008 ficou muito claro que o modelo neoliberal fracassou, mas, por outro lado, as medidas tomadas para tentar sair da crise, principalmente na Europa, tentam salvar o mercado e, no geral, demonizar os políticos. Os casos da Grécia e da Itália, nos quais houve uma solução tecnocrática que tem ignorado os ditames da política democrática, demonstram que é urgente retomar a problemática da relação entre economia e política, sempre tensa e difícil.

A Economia Política clássica teve nos vínculos entre política e economia um de seus temas centrais. Para o pai fundador do pensamento econômico moderno, Adam Smith, era impensável separar a economia da política. Todavia, foi Marx quem, de forma mais radical, relacionou a emergência do Estado com o desenvolvimento do mercado, as instituições representativas como Parlamento, sistemas eleitorais e partidários com o capitalismo e a dominação da burguesia sobre o conjunto da sociedade. Mesmo não tratando a política como um epifenômeno da economia, como muitos analistas acreditam, Marx não entende a política desvinculada da vida econômica (Pograbinschi, 2009).

Poderiam ser citados outros autores da tradição da Economia Política clássica, como John Stuart Mill, o qual acreditava que era preciso compatibilizar, em alguma medida, política e economia, sem perder suas especificidades, para assim encontrar uma combinação mais virtuosa entre estes dois aspectos da vida social. Mas a partir do século XX, especialmente com a emergência da democracia de massas, tornou-se cada vez mais forte a dissociação, quando não oposição, entre a lógica econômica da eficiência e a lógica da ação política.

Diante da necessidade de se repensar as bases sociais e institucionais do capitalismo após a crise de 2008, este trabalho procura, a partir de revisão bibliográfica, retomar a reflexão sobre as relações entre política e economia, em particular ressaltando como tem predominado na Ciência Econômica, e mesmo na Ciência Política - embora em menor grau e paradoxalmente -, uma visão negativa da lógica política, tomada como a antítese da eficiência institucional.

Grande parte dos autores atuais em Economia vê a política como espaço de irracionalidade, a ação estatal como geradora de ineficiências para o mercado e as práticas democráticas como obstáculos à eficácia das políticas econômicas. O fracasso de uma medida econômica é frequentemente creditado à política e explicado pelo chamado "oportunismo eleitoral" dos políticos sempre preocupados com sua 
reeleição, em atender demandas imediatistas de seu eleitorado, quando não exercitam simplesmente práticas de corrupção.

Procuramos mostrar no presente artigo que a ideia da política como o espaço de irracionalidade e da democracia como antagônica à eficiência econômica está bastante enraizada no pensamento econômico do século XX e também foi exportada para parte importante da Ciência Política, atingindo ainda muitos estudos sobre políticas públicas em geral. Isso porque a maioria dos economistas, mas também de cientistas políticos que estudam os impactos das instituições sobre a estratégia dos atores políticos e sobre os resultados das políticas públicas, argumenta que a governabilidade e a efetiva capacidade decisória do Estado só podem ser garantidas se houver insulamento das decisões econômicas de qualquer interferência política, ou se existirem arranjos institucionais que concentrem poder. Em outras palavras, a governabilidade depende da redução das arenas em que as divergências, os conflitos e eventuais consensos possam surgir e em que a política, como o terreno dos interesses e valores construídos socialmente que se expressam num jogo institucionalizado, possa se manifestar.

Defende-se neste texto um caminho inverso ao das soluções que apartam a política da economia ou reduzem seu campo de atuação e escopo. Para tanto, na primeira parte do texto discutimos como dois autores centrais da literatura econômica deste século, Keynes e Schumpeter, elaboraram uma visão baseada na dicotomia entre democracia e eficiência econômica. Na segunda parte, destacamos como o raciocínio econômico hoje dominante, mais próximo dos axiomas dos neoclássicos ou de uma visão mais puramente neoliberal, espraiou-se para a Ciência Política, particularmente a partir da década de 1950. Este fenômeno estreitou a compreensão do fenômeno político dentro da própria ciência incumbida especificamente de analisá-la, tornando-a também defensora de um modelo baseado no predomínio da "eficiência institucional". Como consequência deste processo, discute-se, na terceira parte, como o paradigma das instituições majoritárias tornou-se hegemônico, embora venha sofrendo cada vez mais críticas. No balanço final do artigo, busca-se recuperar o lugar essencial e legítimo da política democrática em sua relação com o desempenho das instituições e das políticas públicas.

\section{VISÃO NEGATIVA DA POLÍTICA NA DEMOCRACIA DE MASSAS: A POSIÇÃO DOS ECONOMISTAS}

A ideia de que a economia e a política, ou ainda, que a eficiência econômica e a lógica democrática têm objetivos opostos ou mesmo excludentes remonta ao final do século XIX e à imposição de um padrão específico de cientificidade adotado pela Economia naquele momento. Durante mais de um século, o pensamento econômico também manteve a tradição que vem dos gregos, de não dissociar discussões políticas e éticas. Nas palavras de Amartya Sen, o estudo da produção das condições de vida, bem-estar e riqueza não se separava da questão de "como devemos viver?". Nas obras de autores como Adam Smith, Stuart Mill e Marx as 
dimensões políticas e éticas dominavam, mas elas gradativamente vão perdendo importância na teoria econômica.

O ponto de inflexão se dará com a escola neoclássica e especialmente a partir da influência de Leon Walras, economista com formação inicial em engenharia que enfatizou a tendência, hoje predominante nos estudos econômicos, de formalização matemática, transformando a Economia Política em Ciência Econômica (Sen, 1999).

Na percepção aguda de Gunnar Myrdal, a pretensão à cientificidade por parte dos economistas levou-os a definir como tarefa da Ciência Econômica a descoberta de "leis naturais" e a introduzir implicitamente princípios normativos sob a forma de "conceitos" gerais.

"Operando com definições que pretendem ser universalmente válidas, frequentemente se tem logrado fazer com que um princípio político implícito pareça logicamente 'correto' [...] O perpétuo jogo de esconde-esconde em Economia consiste em esconder a norma no conceito." (Myrdal,1997, p. 212, grifos nossos)

De forma contundente, Myrdal mostra ainda que a "naturalização" desta ciência social fez com que os juízos de valor ficassem tacitamente subentendidos atrás de conceitos construídos "logicamente". Essa "naturalização" se manifesta ainda no horror que os economistas têm do conflito, fazendo com que a ideia de harmonia (ou equilíbrio) permeie todas as ramificações e a estrutura conceitual de sua disciplina.

Descaracterizando, assim, a Economia como Ciência Social, tal visão de cientificidade implica também a ideia de uma relação de neutralidade em frente à política e aos valores. E ainda a rejeição da política ao negar o conflito social que é sua essência.

“Na economia, sempre existiu a propensão a encobrir conflitos de interesses. Isso é perfeitamente compreensível. As inspirações filosóficas da Economia Política - a filosofia da lei natural e sua ramificação inglesa, o utilitarismo - provém de uma crença na harmonia social, e suas recomendações práticas pressupõem essa harmonia. Como vimos, isso é o resultado lógico de sua maneira singular de construir uma filosofia moral: graças à ideia de harmonia, a conduta real e moral igualmente pode ser deduzida da 'natureza humana' ou, na terminologia utilitarista, de prazer e dor." (Myrdal, 1997, p. 213, grifos nossos).

Este quadro intelectual permite entender a rejeição da política por parte dos economistas e a ideia predominante entre muitos deles de uma superioridade da racionalidade econômica em frente à "racionalidade" política, ou melhor, em frente a sua irracionalidade em termos da eficiência econômica.

O próprio conceito de eficiência, tal como definido na economia, em termos do ótimo de Pareto, implica a negação da ética, como já mostrou Amartya Sen. 
Entendido como a situação na qual ninguém pode melhorar seu estado sem piorar o de alguma outra pessoa, este conceito passa a ser o único critério de julgamento na economia.

"Um estado social pode estar no ótimo de Pareto havendo algumas pessoas na miséria extrema e outras nadando em luxo, desde que os miseráveis não possam melhorar suas condições sem reduzir o luxo dos ricos.” (Sen, 1999, p. 48).

É interessante observar que mesmo os economistas mais críticos em relação ao uso exclusivo da noção paretiana de eficiência alocativa e que propõem adicionar outros conceitos (como, por exemplo, o de eficiência seletiva) não rejeitam totalmente tal critério. Assim, enfocando os problemas normativos decorrentes da política da concorrência, na perspectiva teórica neoshcumpeteriana evolucionária, Mário Possas afirma:

“[...] A rejeição do uso exclusivo de um critério de análise em termos de eficiência alocativa não implica necessariamente quer a rejeição de supostos princípios sólidos de lógica econômica, quer a sujeição da análise antitruste a critérios - e.g., distributivos — 'políticos' ou até 'populistas', como às vezes se diz, de julgamento e decisão. (Possas, 2004, p. 77)”

“(Nesta discussão) é importante não perder de vista dois aspectos essenciais: (i) o problema não é a adoção em si do critério de eficiência alocativa, mas sua exclusividade; (ii) e não se trata de apoiar toda e qualquer redistribuição de excedente para o consumidor - o que pode ser prejudicial, por exemplo, à capacidade de investimento e ao estímulo à inovação por parte das empresas - mas apenas de reconhecer que os efeitos redistributivos não devem ser negligenciados a priori.” (idem, p. 84)

"A rigor, a principal limitação do conceito de eficiência alocativa decorre não de sua fundamentação lógica, que é sólida, ou metodológica (individualista) que pode até ser aceitável, mas econômica, ligada umbilicalmente à teoria do equilíbrio geral competitivo, por meio dos teoremas fundamentais de bem-estar de Pareto.” (Ibidem, p. 89).

Aqui, a crítica não se refere à ausência de critérios éticos, como faz Amartya Sen, ou ainda, na linguagem econômica, a "externalidades". Ela se refere apenas à exclusividade do critério paretiano: em um mundo de concorrência "imperfeita", a ideia de equilíbrio geral não é inteiramente adequada e deve ser completada pela visão de concorrência "schumpeteriana", incorporando nas práticas de inovação o conceito de eficiência seletiva das empresas.

Assim, não se renega a substância do princípio alocativo, supostamente fundado na lógica econômica, que, por "natureza", se distingue da lógica política. O critério paretiano continua sólido como princípio de julgamento. Portanto, também nesta perspectiva, a economia e a política são atividades consideradas incompatí- 
veis. O melhor é separá-las ou então "despolitizar" tudo que for possível, reduzindo, ao mínimo, esta prática "irracional e ineficiente".

Tal visão é partilhada por autores de abordagens teóricas diferentes e até mesmo conflitantes como, de um lado, Schumpeter e Keynes e, de outro, os neoliberais, e mais particularmente, os conservadores adeptos da teoria da escolha pública. Em todos eles, o denominador comum é a desconfiança quanto à política democrática na sociedade de massas. Este aspecto pode ser mais bem compreendido recuperando alguns elementos do debate sobre as relações entre democracia e desenvolvimento econômico.

Um dos mais importantes autores da teoria da modernização, Seymour Lipset (1967), afirmava que o regime democrático está relacionado ao desenvolvimento econômico de um país e sua estabilidade dependeria do grau mais elevado de urbanização, educação, comunicação de massa e burocratização aí existente. Em outras palavras, a manutenção de uma ordem democrática só seria possível à medida que transformações econômicas e sociais geradas pelo processo de modernização levassem ao desaparecimento dos conflitos violentos e extremados, ou seja, abrissem possibilidades de resolvê-los de maneira pacífica mediante a competição eleitoral.

Mesmo argumentando em sentido oposto, afirmando que a modernização não levaria necessariamente à democracia, mas poderia gerar o autoritarismo (como ocorreu em vários países latino-americanos nos anos 1960 e 1970), Samuel Huntington (1968) construiu sua análise na mesma linha de reflexão. Para ele, de linha mais conservadora, a modernização causaria instabilidade política e consequentemente quebra da ordem democrática nas sociedades em que o desenvolvimento econômico não fosse suficiente para gerar distribuição de renda, senão em detrimento do investimento. Em outras palavras, os conflitos decorrentes de demandas sociais que não poderiam ser atendidas pelo baixo nível de desenvolvimento econômico levariam à repressão política e à ruptura da ordem democrática.

Assim, para estes autores, a despeito das diferenças internas de sua argumentação, a democracia é vista como o resultado de processos estruturais que independem da ação dos indivíduos. Esta concepção de que a democracia é processo que decorre inevitavelmente do desenvolvimento econômico e social não é rara nas ciências sociais. Desde Tocqueville, em sua obra clássica Democracia na América, ela é partilhada por vários autores. Entre os economistas, Schumpeter, um de seus mais importantes analistas, também vê a democracia como o resultado do desenvolvimento das sociedades de massa. Pretendendo formular uma teoria que ele denomina realista ou pragmática da democracia para se contrapor às concepções normativas dos clássicos do século XVIII, Schumpeter é bastante cético com relação às chances de sucesso das democracias na gestão da coisa pública.

Rejeitando a crença na existência de uma vontade autônoma dos cidadãos racionais e com capacidade de discernimento próprio, Schumpeter afirma que, na democracia de massas, a vontade dos eleitores é manipulada pelo mercado e pela publicidade, de modo que os indivíduos são maus juízes de seus próprios interesses 
de longo prazo e indiferentes com relação às questões públicas. Em suma, desconfia da capacidade das massas e dos políticos escolhidos por elas.

Por essa razão, para que um governo democrático possa funcionar em uma sociedade de massas, em que há o poder avassalador do mercado, a corrupção e a fabricação da "vontade geral”, Schumpeter indicava ser necessárias três condições fundamentais:

1) limitação dos assuntos submetidos à consulta dos eleitores;

2) autocontrole dos políticos e dos grupos sociais, restringindo pressões sobre o governo;

3) por fim, mas não menos importante, a existência de uma burocracia bem treinada, com forte espírito de corpo e capaz de guiar e instruir os políticos.

Portanto, a solução "realista" para o melhor governo, em geral, e para o governo da economia, em particular, é a completa a autonomia ou insulamento dos técnicos, protegendo-os do sistema político e da pressão das massas incapazes de discernimento sobre os assuntos públicos (Schumpeter, 1971).

A crítica que Schumpeter faz da teoria clássica normativa (baseada em valores) para apresentar sua teoria, por ele denominada de realista (ou seja, baseada em fatos) contém um problema analítico. Como alguns autores já apontaram, “um fato não refuta um valor" (Lukes, 1977), ou, nas palavras de um importante liberal como Giovani Sartori, "uma opção valorativa é independente de um estado de fato" (Sartori, 1994). Na verdade, atrás desta concepção realista, escondem-se, implicitamente, crenças e valores, como Myrdal já apontou. Essas crenças, de cunho conservador, consideram inúteis, perversas ou ameaçadoras quaisquer tentativas de mudanças da ordem social. No brilhante estudo sobre duzentos anos de retórica da intransigência, Albert Hirschman indica que a extensão da cidadania política, a instituição do sufrágio universal e a formação de partidos de massa foram mudanças que mobilizaram profundamente o pensamento conservador desde meados do século XIX (Hirschman, 1992). Ou seja, na visão de Schumpeter, a democracia não é o que seus formuladores do século XVIII e XIX pensaram, mas é um simples jogo de concorrência entre elites para atrair o voto de seus eleitores. O que, para ele, não é indesejável, uma vez que o povo e mesmo os políticos eleitos não têm capacidade para decidir sobre assuntos cada vez mais complexos ${ }^{1}$.

Também Keynes compartilhava da ideia de que, para os males da política democrática, a solução estava nas mãos da tecnocracia. Skidelski, um de seus mais famosos biógrafos, relata que diante de indagações de técnicos do Tesouro inglês a respeito de como controlar ou restringir decisões sobre gastos públicos no contexto de rompimento do padrão-ouro, o grande economista teria respondido: "Confiemos na inteligência responsável dos técnicos". Com isso, comenta o biógrafo, ele superestimou a possibilidade de uma gestão econômica racional pelos governos democráticos (Skidelski, 1977).

\footnotetext{
${ }^{1}$ Para uma crítica mais extensa da visão política de Schumpeter e de seu modelo de democracia, ver Miguel, 2002.
} 
Assim, tanto Keynes quanto Schumpeter acreditavam que os políticos deveriam deixar nas mãos de burocratas ou especialistas as decisões técnicas. Mesmo reconhecendo a necessidade inevitável da presença do Estado para gerir o mercado, esta ação estatal não deveria ser orientada pela lógica democrática, da disputa e negociação de interesses, mas deveria ser feita de forma burocratizada, ou seja, despolitizando a gestão da macroeconomia.

Cabe ressaltar que Schumpeter e Keynes são economistas imprescindíveis para o entendimento da economia contemporânea, adotando, inclusive, posições que vão de encontro à visão reducionista sobre o funcionamento do mercado presente na microeconomia neoclássica. Porém, mesmo com os avanços inegavelmente produzidos por ambos, a concepção acerca da política manteve-se neles como negativa e limitadora do campo de atuação da democracia.

Visões ainda mais negativas da política foram produzidas pelo movimento na Economia, iniciado na década de 1950, que redundou na escola do Public Choice. O interessante é notar que pressupostos presentes nesta corrente depois foram exportados para a Ciência Política, gerando uma concepção do ato político tão reducionista quanto na seara dominante entre os economistas do século XX.

\section{A “COLONIZAÇÃO” DA CIÊNCIA POLÍTICA PELA ECONOMIA: A EXPANSÃO DA CONCEPÇÃO DICOTÔMICA ENTRE EFICIÊNCIA E DEMOCRACIA}

Uma importante parcela da Ciência Política durante o século XX continuou na trilha dos clássicos, defendendo tanto o entendimento das características especificas do mundo político, como sua legitimidade quando regida pela lógica democrática da disputa regrada de interesses e valores, em busca da negociação por consensos possíveis. Entre o que seguiram esta linha, pode ser citada, por conta de sua enorme influência, a obra de Robert Dahl. O seu trabalho realçou que a democracia não é meramente um resultado do desenvolvimento da sociedade capitalista, uma vez que a construção democrática também precisa ser entendida pelo ângulo da autonomização da política.

Sem desprezar os argumentos da teoria da modernização, Dahl (1997) afirma que o acesso e o controle sobre os recursos de poder são variáveis centrais para a democratização das sociedades que se tornaram crescentemente diferenciadas e plurais. Mesmo considerando que a consolidação da democracia tenha a ver com as transformações econômicas ou sociais, como afirmavam os teóricos da modernização, a ordem democrática para Dahl tem também autonomia e uma dinâmica própria, relacionada à extensão da participação política dos cidadãos e do grau em que a contestação (ou oposição) é tolerada na cultura política e concretizada nas instituições ${ }^{2}$.

\footnotetext{
${ }^{2}$ Vale a pena ler os comentários de Fernando Limongi no prefácio da edição brasileira à obra
} 
A dinâmica específica da esfera política se manifestará na ênfase por parte de Dahl do comportamento racional dos atores políticos e de suas estratégias para manter ou romper com o jogo democrático. Retoma, assim, o enfoque realista na linha de Maquiavel, segundo o qual a política é uma esfera de atividade humana com lógica própria. Portanto, a estabilidade da democracia não depende só de transformações estruturais, mas também do jogo político e de sua dinâmica.

Cabe frisar que se o trabalho de Robert Dahl não perde de vista o peso das mudanças estruturais, vários de seus seguidores levaram ao extremo a noção de autonomia do político, entendida como sua completa separação em frente às condições societárias e econômicas. Dessa forma, distanciam-se muito da visão dahliana, empobrecendo-a.

É interessante destacar que esta autonomia extremada da política em frente aos constrangimentos estruturais (econômicos e sociais) será feita pelos adeptos da chamada teoria econômica da democracia, de forma até irônica, justamente no momento em que aderem às premissas da análise econômica. $\mathrm{O}$ inaugurador desta corrente foi Antony Downs, com seu livro Uma Teoria Econômica da Democracia, cuja primeira edição foi de 1957.

Downs constrói sua premissas teóricas modelando a atuação dos atores, no que se refere à sua participação política e decisão de votar, a partir das mesmas categorias utilizadas pela microeconomia, ou seja, da mesma forma que os economistas neoclássicos imaginam os consumidores e as firmas atuando no mercado ${ }^{3}$. Configura-se, então, uma situação de completa "colonização" das análises políticas pelas categorias dominantes na Economia ${ }^{4}$.

Mesmo diante das contribuições dos teóricos do neoinstitucionalismo econômico que fazem reparos ou questionamentos parciais aos pressupostos neoclássicos (levando em conta os problemas de racionalidade limitada, assimetria informacional, custos de transação etc.), ainda há analistas na Economia e na Ciência Política que continuam formulando modelos explicativos nos quais os cidadãos são vistos como indivíduos que apenas satisfazem seu autointeresse. Alguns exemplos bastam para ilustrar. Assim, Downs explica não só a existência dos lobbies no sistema americano e a submissão do governo a eles, mas também a "demanda” por ideo-

Poliarquia de Robert Dahl, publicada pela Edusp em 1997. Trata-se de análise muito benfeita da obra, embora interpretando a teoria democrática de Dahl como uma ruptura demasiado radical com relação à teoria da modernização. Em outras palavras, Limongi não destaca que a autonomia da esfera política para aquele teórico não implica a desconsideração das transformações estruturais que levam ao desenvolvimento de uma sociedade plural como base para as democracias contemporâneas.

${ }^{3}$ Cabe relembrar que a abordagem microeconômica formulada originalmente pelos neoclássicos define-se pelas hipóteses de comportamento racional, maximizador e autointeressado, de equilíbrio do mercado e de estabilidade das preferências empregadas de maneira firme e definitiva.

${ }^{4}$ Como Gary Backer afirmou, nos anos 1980 "a abordagem econômica é uma abordagem global, que pode aplicar-se a todos os comportamentos humanos” (apud Sweddberg, 1994). 
logia por parte dos eleitores a partir de cálculo racional dos atores políticos (lobistas, governo ou eleitores) para reduzir custos de informação.

"When knowledge is imperfect, effective political action requires the use of economic resources to meet the cost of information. Therefore, those who command such resources are able to swing more than their proportional weight politically. This outcome is not the result of irrationality or dishonesty. On the contrary, lobbying in a democracy is a highly rational response to the lack of perfect information, as is government's submission to the demands of lobbyists. To suppose otherwise is to ignore the existence of information costs. [...] Thus lack of information creates a demand for ideologies in the electorate. Since political parties are eager to seize any method of gaining votes available to them, they respond by creating a supply. Each party invents an ideology in order to attract the votes of those citizens who wish to cut costs by voting ideologically." (Downs, 1984, p. 17)

Também examinado as condições de estabilidade democrática a partir de uma visão de equilíbrio no mercado político e usando a perspectiva da teoria dos jogos, Adam Przeworski (1994) mais recentemente indicou que

“[...] A democracia está consolidada quando a adesão — agir de conformidade com a estrutura institucional - constitui o estado de equilíbrio das estratégias descentralizadas de todas a forças políticas relevantes [mas] são restritas as condições dentro das quais a democracia se torna um estado de equilíbrio entre estratégias descentralizadas de forças políticas autônomas. É por isso que a democracia tem-se revelado historicamente uma forma frágil de organização dos conflitos políticos." (p. 46 e p. 56).

Todavia, a análise econômica da política, como expressão do "imperialismo" da Economia, encontra sua forma mais extremada (e até mais grosseira) na Teoria da Escolha Pública (Public Choice) a qual, a despeito de algumas ressalvas à ortodoxia, nada mais é do que a mera extensão da teoria neoclássica ao processo político. Para Buchanan, principal formulador desta abordagem, a política deve ser encarada como uma troca e analisada em termos de mercado. Portanto, os atores políticos são indivíduos como outros quaisquer, que se comportam de forma racional, buscando maximizar seu autointeresse: o político é um vendedor de programas políticos e os indivíduos - eleitores - compradores destes "produtos". Por sua vez, a preferência dos burocratas, também vistos como atores racionais que buscam maximizar seu autointeresse, é ampliar seu espaço de poder e os recursos à sua disposição no aparato governamental. Dessa forma, o Estado terá uma tendência crescente à expansão e seus atores principais tenderão a ser rent-seekers (Moe, 1979).

Construindo sua teoria no quadro de críticas ao keynesianismo e ao Welfare State, Buchanan objetiva mostrar que também o mercado político tem suas falhas e, com isso, procura fornecer fundamentos teóricos para limitar o papel do Estado. 
Como políticos e burocratas são sempre seguidores de uma lógica rent-seeking, quanto menor o Estado, melhor para a coletividade. (Evans, 1993).

Portanto, por razões bastante diversas daquelas de Schumpeter e Keynes (mais próximos de certas variantes de social-democracia), os autores da Escolha Pública tornam-se portadores do credo neoliberal, cujo mote também é a despolitização das decisões governamentais, mas com uma diferença importante. Desconfiando não só dos políticos, mas também dos burocratas, o Public Choice propõe que a despolitização das decisões sobre matérias macroeconômicas não deve ocorrer mediante sua transferência para as mãos da burocracia, como propunham Keynes e Schumpeter, mas sim por meio de mecanismos de mercado (Buchanan, Rowley e Tollison, 1987).

Depois de mais de duas décadas de hegemonia neoliberal, no entanto, e ainda no quadro de imperialismo da análise econômica da política, começaram a surgir a partir do final dos anos 1990 manifestações contrárias a esta concepção reducionista da política e da sua relação com a Economia. A própria concessão do Prêmio Nobel a Amartya Sen em 1998, depois do fiasco da premiação, no ano anterior, de economistas especializados em derivativos cujas teorias se mostraram incapazes de prever crises no mercado financeiro, indica que alguns temas menos convencionais no paradigma econômico (como ética, ideologia etc.) começam a chamar a atenção. Criticando certos pressupostos da teoria econômica, Sen afirmou em seu estudo sobre Ética e Economia: "O egoísmo universal como uma realidade pode muito bem ser falso, mas o egoísmo universal como um requisito da racionalidade é patentemente um absurdo" (sen, 1999, p. 32).

Também a Sociologia Econômica, que desde a morte de Weber até o final do século $\mathrm{XX}$, não atraía muitos praticantes, começa neste contexto a se expandir nos meios universitários americanos e no Brasil. Despertando-se para outras dimensões da vida social, os economistas passam gradativamente a levar em conta que os atores econômicos estão inseridos na sociedade e em contexto político-institucionais que afetam decisivamente seus comportamentos (Granovetter, 1974; Swedberg \& Granovetter, 2003; Abramovay, 2004).

É neste contexto que a nova economia institucional (NEI) se afirma ${ }^{5}$. Ao reconhecer o peso das instituições na vida econômica, a NEI pode ser vista como uma mudança de certa forma significativa no padrão de relação entre a Economia e a Política e na visão que os economistas têm da política, especialmente em frente à maneira extremada de "colonização", como fazem os teóricos da Public Choice. Mesmo não rompendo totalmente com o paradigma neoclássico, a análise institucionalista suaviza a estilização do comportamento humano, tomado como maximizador do autointeresse. Ao contrário, a NEI olha a ação dos indivíduos ampliada pela lente de outras dimensões societárias, das normas, dos constrangimentos morais, dos valores.

\footnotetext{
${ }^{5}$ Procurando entender o desempenho econômico de diferentes países através da história, Douglass North, ganhador do prêmio Nobel e um dos principais teóricos do institucionalismo na Economia, afirma que o comportamento humano é mais complexo do que imagina a visão neoclássica, e enfatiza o peso das instituições, ou seja, das regras formais e informais que, mesmo não sendo eficientes economicamente, reduzem a incerteza e os custos de transação.
} 
É igualmente neste quadro que têm surgido críticas às chamadas virtudes do mercado, mostrando que desprovida de "valores extramercado", a economia de mercado não se sustentaria no longo prazo $^{6}$. Nas palavras agudas do jornalista econômico Robert Kuttner:

"Em certo sentido, é o mercado que tira vantagem dos valores extramercado que tornam nossa sociedade de mercado suportável, temperando o oportunismo incansável recomendado pelo modelo de mercado. Normas de civilidade são um bem público. Sem elas, o mundo degeneraria numa sociedade de suspeita mútua permanente [...] Em vez de um mundo comercial relativamente prazeroso, precisaríamos nos manter em guarda permanente contra achaques. As falências proliferariam. Os bancos teriam que cobrar juros mais altos para compensar o oportunismo generalizado. Garantias explícitas teriam que ser formuladas para cada transação [...] O aperto de mãos se tornaria inútil.” (Kuttner, 1998, p. 99).

Portanto, os autores neoinstitucionalistas concordam que a racionalidade e as motivações pautadas pela maximização do autointeresse não são as únicas presentes nos indivíduos, nem necessariamente as principais. Orientações éticas e arranjos institucionais pelos quais os interesses mais amplos da sociedade são filtrados mostram-se decisivos para o próprio desempenho econômico.

Não obstante, mesmo questionando certas premissas da teoria econômica neoclássica, as discussões que enfatizam o peso das instituições, das estruturas de incentivos e punições que constrangem o comportamento dos atores econômicos ou políticos, que podem ser classificados como neoinstitucionalistas da escolha racional (matizada ou não), padecem frequentemente de vários problemas da teoria econômica da democracia. É o que tentaremos desenvolver a seguir.

\section{O DEBATE EM TORNO DOS ARRANJOS INSTITUCIONAIS DAS DEMOCRACIAS CONTEMPORÂNEAS: O PREDOMÍNIO DO MODELO DA GOVERNABILIDADE MAJORITÁRIA E A QUESTÃO DA EFICIÊNCIA INSTITUCIONAL}

A visão predominante nos estudos sobre as condições institucionais necessárias para que as decisões governamentais atinjam os objetivos propostos supõe a con-

\footnotetext{
${ }^{6}$ Como já se mostrou, talvez com alguma dose de otimismo: "O chamado imperialismo econômico que ameaçava submeter à sua ordem própria o conjunto das ciências sociais revelou fôlego curto: se em meados dos anos 1980, Jon Elster postulava o princípio de que 'todos os fenômenos sociais, sua estrutura e sua mudança são, em princípio, explicáveis por caminhos que envolvem indivíduos', hoje, seu próprio programa de pesquisa está francamente voltado para o estudo das instituições" (Abramovay, 2004, p. 3). Este autor cita o artigo de Elster publicado na revista Sciences Humaines e cujo título revela a própria trajetória intelectual do teórico do individualismo metodológico: "Da racionalidade às normas".
} 
centração de poderes em arenas decisórias restritas, ou a redução do número dos atores com poder de veto, os veto players, para usar expressão bem conhecida de Tsebelis (1997). Como bem argumentou Marcus André Melo (2007), as atuais pesquisas empíricas sobre democracia têm, em sua maior parcela, inspiração num modelo normativo implícito: o paradigma majoritário, baseado na concentração de poder.

Segundo esta concepção, a excessiva fragmentação do poder e o grande número de participantes comprometeriam as decisões, fazendo com que os objetivos desejados fossem desvirtuados ou não fossem atingidos. Este é o argumento que tem mobilizado as inúmeras críticas a respeito dos problemas de governabilidade do presidencialismo, especialmente quando associado ao multipartidarismo e ao federalismo. Como se sabe, o presidencialismo, desde sua origem, com os founding fathers do sistema americano, expressou um arranjo institucional que busca evitar a tirania, mesmo que em detrimento da capacidade decisória (Stepan \& Skach, 1993; Linz, 1990; Shugart \& Mainwaring, 1997).

Portanto, afirma-se na literatura a existência de um claro trade-off nos arranjos institucionais entre governabilidade versus representação. Inúmeras citações nesta linha de argumentação podem ser transcritas. Limitamos apenas três, de trabalhos de autores bastante representativos:

"Thus we end where we began, with the idea that the choice of democratic institutions entails significant tradeoffs. [...] As a society's heterogeneity increases, a system with a greater number of effective vetoes will see increasing risk of stalemate as well as an increasing costliness to a legislative strategy that emphasizes private-regarding policy." (Cox \& Mccubbins, 2001 p. 63, grifos nossos)

““...Proposals that survive the legislative process emerge disfigured by substantive concessions and weighted down by pork barrel side payments." (Ames, 2002 p. 213)

“...With representativeness maximized, voters are presented with a wide range of parties on several salient issues dimensions, but the probability that governments will be formed only after post-election bargaining means that voters are apt to have difficulty identifying the likely governmental options at election time." (Shugart 2001, pp. 29-30, grifos nossos)

As visões implícitas nestas citações contêm a afirmação de que quanto mais heterogênea for uma sociedade, mais risco de paralisia decisória terá aquele sistema político que contemplar suas minorias e dar-lhes poder de veto. Além disso, supõem ainda que a maior representação de forças políticas, produzindo governos de coalizão pós-eleitoral, irá não só descaracterizar as agendas governamentais, mas igualmente dificultar a identificação da responsabilidade política dos governantes. Estas afirmações exprimem uma concepção restrita do processo de accountability, que se funda na habilidade dos governantes de tomar decisões (de preferência rápidas 
e sem negociações que desfigurem os projetos iniciais), na habilidade de implementá-las e na avaliação dos governantes exclusivamente ou quase exclusivamente pelo processo eleitoral.

Tais afirmações exprimem um ideal majoritário de democracia, nos termos definidos por Lijphart (1999). Confrontando o desempenho da democracia majoritária, em que o poder está mais concentrado, com a performance da democracia consociativa, em que o poder está mais fragmentado, Lipjhart, em amplo estudo empírico sobre as democracias contemporâneas e contrariando a literatura convencional, indica que a rapidez de decisão alcançada pela redução do número de atores políticos com poder de veto não necessariamente gera melhores resultados nas políticas governamentais - nos casos estudados por ele, tanto em termos do alcance de resultados econômicos quanto em termos de controle da violência. Além disso, diz o autor:

"Policies supported by a broad consensus, furthermore, are more likely to be carried out successfully and to remain on course than policies imposed by a 'decisive' government against the wishes of important sectors of society.” (Lijphart, 1999 p. 260)

Também questionando normativamente a visão majoritária de democracia centrada na dicotomia entre representação proporcional/fragmentação do poder versus governabilidade, estudos mais recentes têm mostrado que a estabilidade das políticas públicas vai depender de sua coerência interna. E mais, a implementação bem-sucedida dessas políticas pode ser aumentada e não reduzida, como se pensa geralmente, em função da existência de estruturas institucionais que exijam amplas negociações e debate entre a pluralidade de atores políticos durante o processo decisório de tais políticas.

Um primeiro exemplo dessa argumentação está no trabalho de Stark \& Brustz (1998). Examinando as bases institucionais da coerência das políticas adotadas no Leste Europeu no pós-socialismo, os autores indicam que a capacidade de efetivamente realizar programas de reforma pode ser aumentada (e não reduzida) quando o Poder Executivo é menos concentrado, ou seja, é mais constrangido a prestar contas de suas decisões às diversas forças políticas no Parlamento e na sociedade organizada. Tendo que debater e negociar suas propostas com outros atores, os policymakers aumentam a compreensão dos problemas, ampliam a capacidade de obter informações críticas, corrigindo erros de cálculo que, na ausência deste processo, só apareceriam no momento da implementação e, portanto, com menor possibilidade de correção. Isto encoraja, ainda, os formuladores a pensar vários passos à frente nos jogos estratégicos da política pública.

Recusando igualmente a "explicação canônica" de que o sucesso de reformas econômicas exige a autonomia concentrada do Poder Executivo e o insulamento de suas elites técnicas, Tavares de Almeida (1997) mostra que o processo de privatização no Brasil dos anos 1990 foi um processo intensamente negociado com o Congresso. No plano comparativo, este argumento torna-se mais forte a partir do 
trabalho de Vicente Palermo (1998), que mostrou que as reformas à brasileira, cotejadas com o processo argentino, foram mais negociadas, graduais e incrementais, gerando, comparativamente, resultados mais efetivos e duradouros no Brasil (Palermo, 1998).

Neste sentido, os processos decisórios inclusivos possibilitam resultados mais eficientes do que aqueles originários de arenas insuladas e de poder concentrado porque aumentam a informação tanto do ponto de vista técnico (pois soluções alternativas podem emergir) como do ponto de vista da manifestação das diversidades de preferências e soluções políticas sobre o tema em questão.

A situação em que os governantes são constrangidos institucionalmente a levar em conta uma pluralidade de atores e ao mesmo tempo prestar contar de seus atos ou omissões ao longo de todo o mandato e não apenas no momento de eleição é denominada por Stark \& Brustz de responsabilidade política estendida. Nesta visão não há um trade-off entre representação versus governabilidade, nem tampouco entre representação versus accountability (privilegiada apenas no sentido de clareza do agente responsável), como considera a visão majoritária. Ao contrário, estes princípios democráticos só se efetivam de forma conjunta e complementarmente. Portanto, a efetividade do governo não ocorre em detrimento de sua qualidade democrática, mas junto com ela ${ }^{7}$.

O fato é que evidências empíricas começam a se acumular em direção à ideia de que sistemas políticos mais representativos e/ou de sociedades mais inclusivas em termos de tomadas de decisões podem ter melhores desempenhos econômicos. Mesmo que tais evidências ainda não permitam afirmações seguras relativas aos impactos dos arranjos democráticos consensuais no desempenho governamental ou nos resultados substantivos para a economia e a sociedade, em termos de desenvolvimento econômico, emprego, bem-estar social, entre as variáveis fundamentais, é importante ressaltar que já começa a ser quebrado o pressuposto dominante de que a concentração de poder (que é uma forma de redução da esfera política) seja condição necessária para a efetividade dos governos ou a governabilidade.

Em outras palavras, tal pressuposto exprime, de forma diversa, a mesma dicotomia presente no trade-off entre democracia e eficácia econômica, porque supõe que em arenas decisórias de participantes com diferentes posições ou pontos de vista, os conflitos aparecerão com mais força e no limite vão "desviar" as decisões de seus rumos "corretos", isto é, aqueles indicados pelo saber técnico que se supõe único, já que só há uma "única verdade científica".

\footnotetext{
7 Embora exigindo uma discussão mais aprofundada e uma definição inclusive operacional, consideramos que a qualidade da democracia é o resultado da existência de arranjos institucionais que possam gerar, ao mesmo tempo, um governo com a maior representatividade possível das forças políticas, no qual os governantes executem de forma mais efetiva e eficiente as políticas públicas sinalizadas ou prometidas no processo eleitoral e, não o fazendo, eles sejam constrangidos a prestar contas de forma continuada de seus atos ou omissões. Portanto, representatividade, desempenho governamental e accountability são, aqui, os critérios definidores da qualidade da democracia.
} 
Por fim, é necessário esclarecer que essas reflexões não implicam a ideia de que a fragmentação excessiva de poder seja desejável. O que interessa realçar são os próprios limites intelectuais em que áreas expressivas da Economia e da Ciência Política hoje têm se fechado, ao aderir a certos pressupostos teóricos e metodológicos que optam por uma busca em reduzir o jogo político, e a pluralidade presente nele, ao mínimo. Isto pode ser feito pela via tecnocrática, protegendo arenas de políticas públicas da influência dos políticos e dos interesses dos atores sociais, como também pela opção por um modelo majoritário de democracia.

\section{CONSIDERAÇÕES FINAIS: A INTELIGÊNCIA POTENCIAL DA POLÍTICA DEMOCRÁTICA}

Procuramos mostrar nestas reflexões que o debate contemporâneo sobre democracia e desempenho econômico ou institucional, marcado pela hegemonia de uma concepção economicista do mundo, majoritariamente vê a política e as práticas democráticas como obstáculos ao governo eficiente. A proposição de Schumpeter para o bom funcionamento do governo nas democracias de massas nada mais é do que a despolitização completa das decisões governamentais e sua entrega aos técnicos. Nesta visão, as práticas democráticas devem se submeter aos ditames da eficiência, porque os conflitos, as divergências e os possíveis acordos devem ser substituídos pelo mais "completo e competente conhecimento científico". Em outras palavras, a ciência deve substituir a política como a solução para os problemas complexos da vida coletiva.

Há quase um século Max Weber (1990) já nos havia alertado para os perigos dessa visão, afinal as decisões coletivas exigem dos políticos e dirigentes públicos uma ética da responsabilidade que deve procurar construir consensos e calcular os resultados de suas ações - tão ou mais importantes do que as intenções dos atores. A adoção deste tipo de comportamento é essencial para as democracias e ele envolve algo que vai muito além do saber científico - embora este seja muito importante como um dos referenciais da definição das políticas públicas. Como definira Weber, escrevendo antes do nazismo e antevendo a possibilidade de desmoralização e abandono dos princípios da política na Alemanha: fora da política não há salvação para a vocação inerentemente autoritária do Estado.

A defesa da importância da política democrática e de seus ditames não nos pode levar a uma nova dicotomia, agora de sinal trocado: a política sobrepujando os critérios de eficiência e desempenho baseados em estudos e avaliações de políticas. Evitando qualquer visão polarizadora, afirmamos aqui, tanto do ponto de vista analítico, quanto do ponto de vista normativo, a possibilidade de conciliação do cálculo econômico com suas exigências de eficiência e com os imperativos do governo democrático. Suporte para esta crença pode ser encontrado nas reflexões dos teóricos da democracia pluralista, como Lindblom e Woodhouse (1993), já contidas não só na epígrafe deste texto, mas igualmente na seguinte passagem, a respeito da inteligência potencial da democracia. 
"The reason why undemocratic processes undermine intelligent policy making is that the quality of political outcomes is not determined primarily by the quality of elite analysts' ideas, nor even by the insights of the most influential political participants. Policy making is political, produced by the interactions of a myriad of participants in a setting of shared power [...] When potential relevant participation is undermined or shut out by systematic biases differentially empowering certain social groups or ideas, less intelligence can be brought influentially to bear" [...] If significantly greater democracy is possible at all in the next century or two, it will have to come about largely via partisan probing and reconsideration, hopefully aided in small but perhaps crucial ways by intellectuals, including professionals.” (Lindblom \& Woodhouse, 1993 pp. 141-142)

Mesmo mostrando os limites da capacidade analítica e da racionalidade técnica para resolver completamente os conflitos de valores e de interesses que têm gerado guerras, violência, pobreza, incapacidades e sofrimento de toda ordem, Lindblom \& Woodhouse afirmam que a racionalidade ou a inteligência do processo democrático consiste na capacidade de incorporar o conhecimento técnico e a análise racional à política e não a sua exclusão recíproca.

Defender este argumento é tanto mais importante em razão da necessidade de superar a atual crise nos Estados Unidos e, sobretudo, na Europa, por um meio de ações que conciliem o conhecimento técnico e a eficiência com a política democrática. Solucionar os atuais problemas por modelos tecnocráticos é uma forma de mostrar o quanto a lógica antipolítica — para não dizer antidemocrática — predominante no período neoliberal ainda vigora sob seus escombros.

\section{REFERÊNCIAS BIBLIOGRÁFICAS}

ABERBACH, J. PUTNAM, R. \& ROCKMAN. B. (1981). Bureaucrats and Politicians in Western Democracies. Harvard University Press, Boston.

ABRAMOVAY, R. (2004). Formas de organização dos mercados: interação social e ciências humanas. FEA/USP, mimeografado.

ALESINA, A., ROUBINI, N. e COHEN, G. (1997). Political cycles and the macroeconomy. Cambridge University Press.

BARRY, B (1970). Sociologists, Economists and Democracy. Collier-Macmillan Limited, London

BELLUZZO, L.G. (1993).”Economia, Estado e Democracia”. Lua Nova. Revista de Cultura e Política. n. $28 / 29$.

BEHN, R (1998).”O novo paradigma da gestão pública e a busca da accountability democrática” Revista do Serviço Público, n. 4, out-dez.

BOBbIO, N. (1992). O Futuro da Democracia. Uma Defesa das Regras do Jogo. Editora Paz e Terra, São Paulo.

BUCHANAN, ROWLEY e TOLLISON (1987). “Government by red ink” In: Deficit. Basil Blackwell.

CHAN, S. (2002). Liberalism, Democracy and Development. Cambridge University Press.

COX \& McCubbins (2001).” The institutional determinantes of economic policy outcomes” In: HAGGARD \& McCUBBINS (2001) Presidents, Parliaments and Policy. Cambridge University Press.

DAHL, R. (1997). Poliarquia. Edusp, São Paulo. 
DAHL, R (1985). Um Prefácio à Democracia Econômica, Jorge Zahar editores, Rio de Janeiro.

DAHL, R. (1982). Dilemmas of pluralist democracy. Autonomy versus control. Yale University Press. DOWNS, A. (1999). Uma teoria econômica da democracia. Edusp, São Paulo.

DOWNS, A. (1984)." An economic theory of political action in a democracy" In: Fergusons \& Rogers(eds.) The political economy. Readings in the politics and economics of American public policy. M.E.Sharpe, Inc. New York.

EVANS, P. (1993). “O Estado como problema e o Estado como solução” Revista Lua Nova, n. 28/29.

GRANOVETTER (1985). "Economic action and social structure: the problem of embeddedness" In: American Journal of Sociology, n. 91, November.

HAGGARD, S. \& KAUFMAN, R. (1995). The political economy of democratic transitions. Princeton University Press.

HAGGARD \& McCUBBINS (2001). Presidents, Parliaments and Policy. Cambridge University Press. HIRSCHMAN, A. (1992). A retórica da intransigência. Companhia das Letras, São Paulo.

HUNTINGTON, S. (1968). Political order in changing societies. Yale University Press.

KUTTNER, R. (1998). Everything For Sale. The virtues and limits of markets. Alfred A. Knoff. New York.

LIJPHART, A. (1999). Patterns of democracy. Government forms and performance in thirty-six democracies. Yale University Press.

LINDBLOM, C. \& WOODHOOUSE, E. (1993) The Policy making process. Prentice Hall.

LINZ, J. (1990). “The perils of presidentialism” Journal of Democracy

LIPSET, S. (1967). O Homem Político. Editora Zahar, Rio de Janeiro.

LUKES, S. (1977). Essays in social theory. MacMillan, London.

MAXFIELD, S. (1997). Gatekeepers of growth. The international poltical economy of central banking in developing countries. Princeton University Press.

MELO, M. (2007). O viés majoritário na política comparada: responsabilização, desenho institucional e qualidade democrática. Revista Brasileira de Ciências Sociais, vol. 22, n. 63, São Paulo.

MIGUEL, L.F. (2002). A democracia domesticada: bases antidemocráticas do pensamento democrático contemporâneo. Revista Dados, vol. 45, n. 3, Rio de Janeiro.

MYRDAL, G. (1997). Aspectos políticos da teoria econômica. Nova Cultural, São Paulo.

MOE, T. (1997). "The positive theory of public bureaucracy" In: MUELLER, D. (ed.) Perspectives of Public Choice. Cambridge University Press.

MUELLER, D. (ed.) (1997). Perspectives of Public Choice. Cambridge University Press.

PALERMO, V. (1998). “Os caminhos da reforma na Argentina e no Brasil” Revista Lua Nova, 45.

POGRABINSCHI, T (2009). O Enigma do Político: Marx contra a Política Moderna. Editora Civilização Brasileira, Rio de Janeiro.

POTERBA, J.M. \& HAGEN, J.V. (orgs)(1999). Fiscal institutions and fiscal performance. Chicago University Press.

SARTORI, G. (1994). A Teoria democrática revisitada, Atica, São Paulo.

SCHUMPETER, T. (1971). Capitalismo, socialismo y democracia. Aguillar, Madrid.

SCHNEIDER, B. R. \& DONE, R. (2000). "The new institutional economics, business associations, and development”. Brazilian Journal of Political Economy, vol. 20, n. 3, July- September.

SHUGARD, M. \& MAINWARING, S. (1997). Presidentialism and Democracy in Latin America, Columbia University Press.

SEN, A. (1999). Sobre Ética e Economia. Companhia da Letras, São Paulo.

SKIDESLKY, R. (1977). “The political meaning of the keynesian revolution'. In: SKEDESLKY, R. (ed.). The End of Keynesian Era. Mcmillan, London.

STARK, D. \& BRUSTZ,L. (1998). "Enabling constraints: fontes institucionais de coerência nas políticas públicas no pós-socialismo". Revista Brasileira de C. Sociais vol 13, n. 36, fevereiro, pp.13-39.

STEPAN, A \& SKACH, C. (1993). "Constitutional framework and democratic consolidation: parliamentarism and presidentialism”. World Politics, 46.

SWEDBERG M. (1994). Une histoire da la sociologie économique. Desclée de Brouwer, Paris.

SWEDBERG \& GRANOVETTER. (2001). The sociology of economic life. Westview Press. 
TAVARES de ALMEIDA, M.H. \& MORA, M. (1997). “A Reforma negociada: O Congresso e a política de privatização". Revista Brasileira de C. Sociais,vol. 12 n. 34, junho.

TONETO, R.(1996). "Buchanan e a análise econômica da política” Revista Lua Nova, n. 38

TSEBELIS,G. (1997).”Processo decisório em sistema políticos: veto players no presidencialismo, parlametarismo, multicameralismoe pluripartidarismo". Revista Brasileira de C. Sociais, vol. 12, n. 34, junho.

WEBER, M. (1990). Ciência e Política: duas vocações. Editora Cultrix. São Paulo.

WHITEHAED, L. (2004).The political dynamics of financial crises in "emerging market' democracies. Trabalho apresentado no 4o. Encontro Nacional da ABCP (Associação Brasileira de Ciência Política), Rio de Janeiro, 21 a 23 de julho de 2004. 